Research Article

\title{
Triazole-Resistant Aspergillus fumigatus from Fungicide-Experienced Soils in Naivasha Subcounty and Nairobi County, Kenya
}

\author{
Edson K. Kemoi $\mathbb{D}^{1},{ }^{1,2}$ Andrew Nyerere, ${ }^{1}$ and Christine C. Bii ${ }^{3}$ \\ ${ }^{1}$ Jomo Kenyatta University of Agriculture and Technology, Nairobi, Kenya \\ ${ }^{2}$ University of Kabianga, Kericho, Kenya \\ ${ }^{3}$ Kenya Medical Research Institute, Nairobi, Kenya \\ Correspondence should be addressed to Edson K. Kemoi; kemoiedson@gmail.com
}

Received 15 September 2017; Revised 6 December 2017; Accepted 3 May 2018; Published 26 June 2018

Academic Editor: Simona Nardoni

Copyright $(2018$ Edson K. Kemoi et al. This is an open access article distributed under the Creative Commons Attribution License, which permits unrestricted use, distribution, and reproduction in any medium, provided the original work is properly cited.

The mainstay in prevention and treatment of aspergillosis is the use triazole drugs. In Kenya, the use of agricultural azole is one of the predisposing factors in development of resistance. One hundred fifty-six (156) experienced soils were collected from agricultural farms and cultured on Sabouraud DextroseAagar. The study isolated 48 yielded Aspergillus fumigatus and 2 A. flavus. All the isolates were subjected to antifungal susceptibility testing against three triazoles: posaconazole, voriconazole, and itraconazole. Out of the isolates, 3 had MIC of 32 and 1 had MIC of 16 against itraconazole, and 1 isolate had MIC of 32 against posaconazole. CYP51A gene was sequenced, and TR34/L98H mutation was identified. Triazole resistance existing in Kenya calls for rational use of azole-based fungicides in agriculture over concerns of emerging antifungal resistance in clinical practice.

\section{Introduction}

Aspergillus species, especially Aspergillus fumigatus, is the most common cause of aspergillosis, which is the second leading cause of death after cryptococcosis in patients suffering from fungal infections [1]. Azole-resistant Aspergillus fumigatus is an evolving global health challenge [2]. It is a frequent colonizer of cavitary lesions in tuberculosis patients and cause of mortality in post-TB treatment cases [3].

Aspergillosis treatment is done by using amphotericin $\mathrm{B}$ or azoles. However, resistance against azoles has been increasingly reported especially from high- and middleincome countries [4-12]. Previous studies from different regions of the world-African region (Tanzania), European region (Netherlands, Belgium, Denmark, and Germany), Asia (Kuwait, India, and Iran), and the USA-have reported multiple sources of azole-resistant Aspergillus fumigatus from soil sample, flower beds, plants, compost, and hospitals and its environs [4, 10, 12-23].

In contrast, limited data are available from low-income countries, especially from sub-Saharan Africa. However, a recent disturbing report of high resistance to azole was reported in Moshi, Tanzania associated with A. fumigatus with TR34/L98H and TR46/Y12F/T289A mutations [20]. The widespread irrational use of azole-based agricultural fungicides in the flower and horticultural industry in Kenya is a significant risk factor for azole resistance. The study aimed to determine the prevalence of triazole resistance among Aspergillus fumigatus from fungicide-experienced soils.

\section{Methodology}

2.1. Study Area. The study was conducted in Nairobi and Naivasha subcounty where horticultural practices and green houses are concentrated. Nairobi is the capital city of Kenya and lies at about $1^{\circ} 17^{\prime} \mathrm{S}$ and $36^{\circ} 49^{\prime} \mathrm{E}$ while Naivasha is located approximately $90 \mathrm{~km}$ northwest of Nairobi. It is located in Nakuru County at $0^{\circ} 43^{\prime} \mathrm{S} 36^{\circ} 26 \mathrm{E}$, and horticulture is the main economy. The trade names of commonly used fungicides include milraz, antracol, mistress, and victory which are broad-spectrum fungicides of ornamental, vegetable, and fruit plants (Figure 1) 


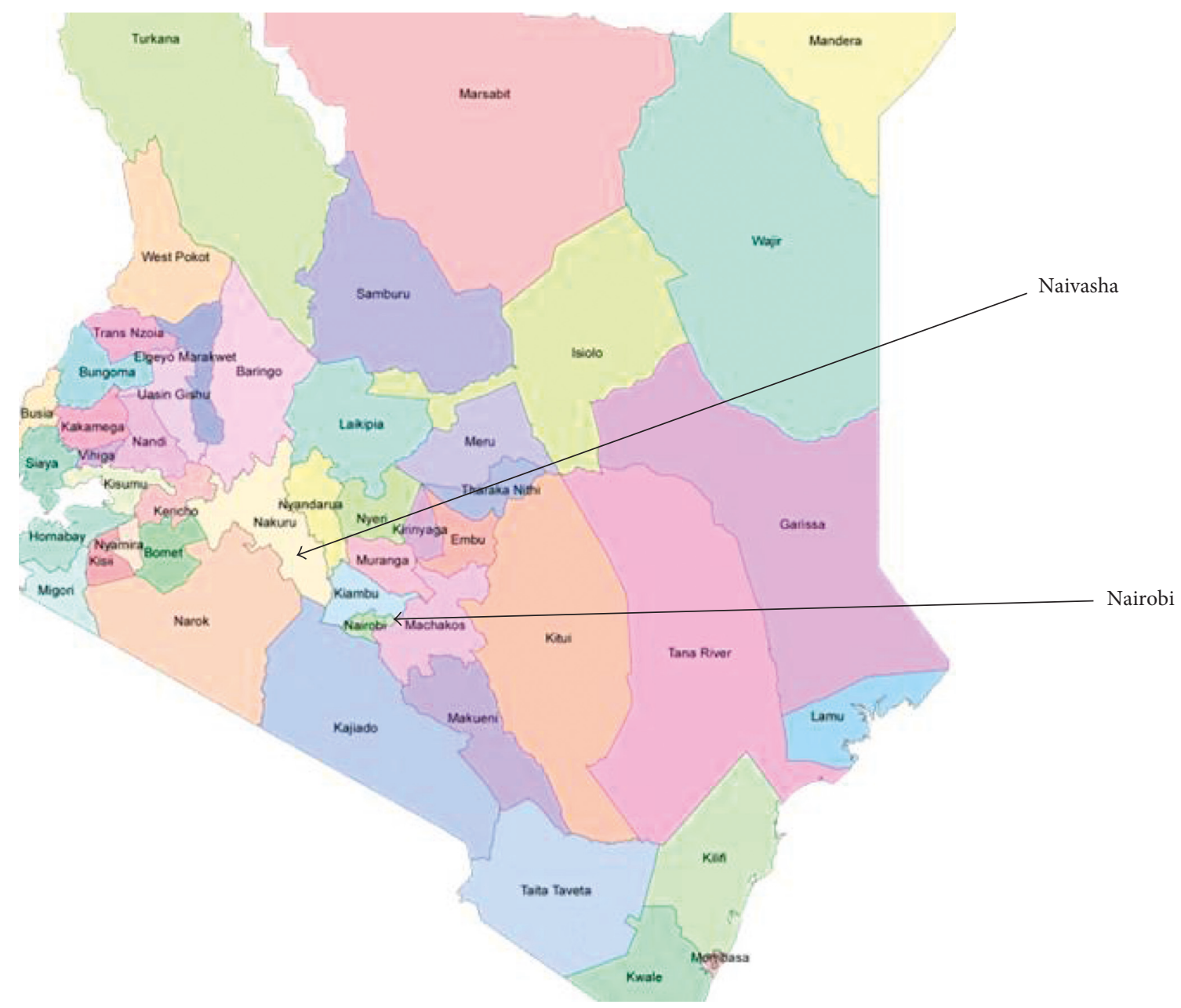

Figure 1: A map showing the study areas. Courtesy of www.mapsofworld.com (accessed 12 January 2015).

2.2. Sampling for Environmental Isolates. A total of 156 samples were collected and analyzed. Approximately $5 \mathrm{~g}$ dry top surface soil from the agricultural site was collected into a sterile $15 \mathrm{ml}$ Falcon tube using a sterile plastic spoon [23]. Samples were transported in a leak-proof packaging in a cool box to the Mycology Laboratory-KEMRI-Center for Microbiology Research for investigation. Clinical isolates were isolated from sputum samples of suspected aspergillosis patients and were archived at Kenya Medical Research Institute, Mycology Laboratory.

2.3. Fungal Culture and Identification. One gram of soil sample was mixed with $5 \mathrm{ml}$ saponin, vortexed, and the debris was allowed to settle. One hundred microliters of the supernatant was transferred to $500 \mu \mathrm{l}$ of sterile normal saline and vortexed. Approximately $100 \mu \mathrm{l}$ of the suspension was cultured onto Sabouraud dextrose agar containing (a). $0.001 \mathrm{mg} / \mathrm{l}$ of itraconazole, (b) $0.001 \mathrm{mg} / \mathrm{l}$ of voriconazole, and (c) without drug (control). All the inoculated plates were incubated for 5 days at $30^{\circ} \mathrm{C}$ [24].

2.4. Broth Dilution Sensitivity Testing. Aspergillus fumigatus growing on azole-supplemented media were subjected to antifungal susceptibility testing against three triazoles: posaconazole (PCZ), voriconazole (VCZ), and itraconazole (ITZ) using the CLSI M38-A2 broth microdilution method [25].

2.5. Sequencing of CYP51A Gene. Aspergillus fumigatus showing high MIC against itraconazole, voriconazole, and posaconazole had their CYP51A gene sequenced for detection of mutation as previously described [26].

\section{Results}

A total 156 fungicide-exposed soil samples were analyzed, out of which 48 yielded Aspergillus fumigatus and 2 A. flavus. Antifungal susceptibility testing against three triazoles, posaconazole, voriconazole, and itraconazole, indicates that 3 isolates had $\mathrm{MIC}=32 \mu \mathrm{g} / \mathrm{ml}$ and other 2 had $\mathrm{MIC}=4 \mu \mathrm{g} / \mathrm{ml}$ against itraconazole, 5 isolates had $\mathrm{MIC}=8 \mu \mathrm{g} / \mathrm{ml}$ and 1 isolate had $\mathrm{MIC}=16 \mu \mathrm{g} / \mathrm{ml}$ against voriconazole, and 1 isolate had MIC of $32 \mu \mathrm{g} / \mathrm{ml}$ and one had $\mathrm{MIC}=16 \mu \mathrm{g} / \mathrm{ml}$ against posaconazole (Table 1 ). Two archived clinical Aspergillus fumigatus from KEMRIMycology were used for comparison (Table 1).

Triazole resistance levels of all of the Aspergillus fumigatus isolates are summarized in Table 2. According to 
TABLE 1: Sources of isolates and MIC against the three triazoles.

\begin{tabular}{|c|c|c|c|c|c|}
\hline Number & Sources & Isolates & MIC against itraconazole & MIC against voriconazole & MIC against posaconazole \\
\hline F1 & Experienced soils & Aspergillus fumigatus & 1 & 0.25 & 0.25 \\
\hline $\mathrm{F} 2$ & Experienced soils & Aspergillus fumigatus & 1 & 0.15 & 0.25 \\
\hline F3 & Experienced soils & Aspergillus fumigatus & 0.5 & 0.5 & 0.06 \\
\hline F4 & Experienced soils & Aspergillus fumigatus & 1 & 0.25 & 0.25 \\
\hline F5 & Experienced soils & Aspergillus fumigatus & 1 & 0.15 & 0.25 \\
\hline F6 & Experienced soils & Aspergillus fumigatus & 4 & 1 & 1 \\
\hline F7 & Experienced soils & Aspergillus fumigatus & 4 & 1 & 1 \\
\hline F8 & Experienced soils & Aspergillus fumigatus & 0.5 & 0.15 & 0.25 \\
\hline F9 & Experienced soils & Aspergillus fumigatus & 0.5 & 0.06 & 0.15 \\
\hline F10 & Experienced soils & Aspergillus fumigatus & 1 & 0.5 & 0.25 \\
\hline F11 & Experienced soils & Aspergillus fumigatus & 0.5 & 0.13 & 0.06 \\
\hline F12 & Experienced soils & Aspergillus fumigatus & 0.5 & 0.06 & 0.06 \\
\hline F13 & Experienced soils & Aspergillus fumigatus & 0.5 & 0.03 & 0.25 \\
\hline F14 & Experienced soils & Aspergillus fumigatus & 0.25 & 0.15 & 0.06 \\
\hline F15 & Experienced soils & Aspergillus fumigatus & 0.5 & 0.15 & 0.25 \\
\hline F16 & Experienced soils & Aspergillus fumigatus & 0.5 & 0.15 & 0.15 \\
\hline F17 & Experienced soils & Aspergillus fumigatus & 0.13 & 0.5 & 0.25 \\
\hline F18 & Experienced soils & Aspergillus fumigatus & 1 & 1 & 1 \\
\hline F19 & Experienced soils & Aspergillus fumigatus & 0.15 & 0.06 & 0.25 \\
\hline F20 & Experienced soils & Aspergillus fumigatus & 0.5 & 0.15 & 0.25 \\
\hline $\mathrm{F} 21$ & Experienced soils & Aspergillus fumigatus & 1 & 1 & 1 \\
\hline F22 & Experienced soils & Aspergillus fumigatus & 0.5 & 0.15 & 0.5 \\
\hline $\mathrm{F} 23$ & Experienced soils & Aspergillus fumigatus & 32 & 8 & 0.5 \\
\hline F24 & Experienced soils & Aspergillus fumigatus & 1 & 0.25 & 0.25 \\
\hline $\mathrm{F} 25$ & Experienced soils & Aspergillus fumigatus & 1 & 8 & 0.5 \\
\hline F26 & Experienced soils & Aspergillus fumigatus & 0.5 & 0.15 & 0.15 \\
\hline $\mathrm{F} 27$ & Experienced soils & Aspergillus fumigatus & 0.5 & 0.03 & 0.06 \\
\hline F28 & Experienced soils & Aspergillus fumigatus & 0.5 & 1 & 0.15 \\
\hline F29 & Experienced soils & Aspergillus fumigatus & 1 & 0.15 & 0.25 \\
\hline F30 & Experienced soils & Aspergillus fumigatus & 0.5 & 0.05 & 0.15 \\
\hline $\mathrm{F} 31$ & Experienced soils & Aspergillus fumigatus & 1 & 0.15 & 0.25 \\
\hline F32 & Experienced soils & Aspergillus fumigatus & 1 & 0.15 & 0.15 \\
\hline F33 & Experienced soils & Aspergillus fumigatus & 0.5 & 0.25 & 0.5 \\
\hline F34 & Experienced soils & Aspergillus fumigatus & 1 & 0.15 & 0.25 \\
\hline F35 & Experienced soils & Aspergillus fumigatus & 1 & 2 & 1 \\
\hline F36 & Experienced soils & Aspergillus fumigatus & 32 & 16 & 1 \\
\hline F37 & Experienced soils & Aspergillus fumigatus & 0.5 & 0.15 & 0.25 \\
\hline F38 & Experienced soils & Aspergillus fumigatus & 0.5 & 0.25 & 0.15 \\
\hline F39 & Experienced soils & Aspergillus fumigatus & 1 & 0.25 & 0.25 \\
\hline $\mathrm{F} 40$ & Experienced soils & Aspergillus fumigatus & 32 & 8 & 32 \\
\hline F41 & Experienced soils & Aspergillus fumigatus & 1 & 0.15 & 0.15 \\
\hline $\mathrm{F} 42$ & Experienced soils & Aspergillus fumigatus & 0.5 & 0.15 & 0.15 \\
\hline F43 & Experienced soils & Aspergillus fumigatus & 0.5 & 0.06 & 0.06 \\
\hline F 44 & Experienced soils & Aspergillus fumigatus & 8 & 8 & 16 \\
\hline F45 & Experienced soils & Aspergillus fumigatus & 1 & 8 & 0.5 \\
\hline F46 & Experienced soils & Aspergillus fumigatus & 0.25 & 0.006 & 0.25 \\
\hline F47 & Experienced soils & Aspergillus fumigatus & 0.06 & 0.25 & 0.25 \\
\hline F 48 & Experienced soils & Aspergillus fumigatus & 0.5 & 0.13 & 0.5 \\
\hline $\mathrm{C} 21$ & Clinical & Aspergillus fumigatus & 4 & 4 & 2 \\
\hline $\mathrm{C} 40$ & Clinical & Aspergillus fumigatus & 2 & 1 & 0.13 \\
\hline
\end{tabular}

Arendrup et al. [27] breakpoints, the percentage of resistance against both itraconazole and voriconazole was $12.5 \%$ and susceptible cases at $87.5 \%$ and $85.4 \%$ against itraconazole and voriconazole, respectively. Against posaconazole, $27.1 \%$ were resistant, $60.4 \%$ were intermediates, and $12.5 \%$ were susceptible.

Three samples with high MIC were subjected to sequence analysis for the detection of mutation in CYP51A in which TR34/L98H was confirmed (Table 3).

\section{Discussion}

In our study, we report the presence of triazole-resistant $A s$ pergillus fumigatus from clinical- and fungicide-experienced soils collected from Naivasha and Nairobi, Kenya. Azoleresistant Aspergillus spp. have been detected worldwide including Asia, Europe, Middle East, Tanzania [20], and Kenya. Kemoi et al. reported prevalence of azole-resistant Aspergillus fumigatus between $19.23 \%$ and $36 \%$ from both naive and 
TABLe 2: Triazole resistance levels of the isolated Aspergillus fumigatus.

\begin{tabular}{lccc}
\hline Resistance & Itraconazole $(n(\%))$ & Voriconazole $(n(\%))$ & Posaconazole $(n(\%))$ \\
\hline Resistant & $6(12.5)$ & $6(12.5)$ & $13(27.1)$ \\
Intermediates & 0 & $1(2.08)$ & $29(60.4)$ \\
Susceptible & $42(87.5)$ & $41(85.4)$ & $6(12.5)$ \\
Total & $48(100)$ & $48(100)$ & $48(100)$ \\
\hline
\end{tabular}

TABLE 3: Sequencing analysis of CYP51A of selected Aspergillus fumigatus.

\begin{tabular}{|c|c|c|c|c|c|c|c|c|c|c|c|c|}
\hline Number & & Mutation & & & & & TR & & & & & Sources \\
\hline$\overline{\text { F36 }}$ & A. fumigatus & TR34/L98H & 14 & 21 & 8 & 32 & 9 & 38 & 8 & 10 & 18 & Environmental \\
\hline F40 & A. fumigatus & TR34/L98H & 14 & 21 & 8 & 28 & 9 & 6 & 8 & 10 & 18 & Environmental \\
\hline $\mathrm{C} 21$ & A. fumigatus & TR34/L98H & 14 & 21 & 8 & 28 & 9 & 6 & 8 & 10 & 18 & Clinical \\
\hline
\end{tabular}

experience soils. However, the study did not sequence CYP51A gene to determine the type of mutations involved [21]. The finding of this study is of great medical implications especially in African environments where resources are limited and effective treatment and early diagnosis are a challenge. Posaconazole, itraconazole, and voriconazole are the first-line drugs used in management and prevention of aspergillosis; hence, detection of environmental isolates resistant to these triazoles poses great challenge in the medical field $[27,28]$.

In Kenya, Naivasha subcounty is known for extensive flower farming with extensive use of fungicides. The use of azole-based fungicide in agriculture introduces antifungal pressure resulting in reduced susceptible fungi and increases azole-resistant strains [29]. Detection of A. fumigatus with TR34/L98H mutation is the first report in Kenya. It has been reported by several authors that isolates with mutations in TR34/L98H region have cross resistance to both medical azole and azole-based fungicides, for example, propiconazole, tebuconazole, difenoconazole, bromuconazole, and epoxiconazole $[4,12]$. The TR34/L98H mutation in gene CYP51A involves the substitution of leucine 98 for histidine L98H and two 34-bp tandem copies in CYP51A gene in the promoter region [10, 30-33].

Azole-based fungicides in the environment have been linked to TR/L98H mutation in Aspergillus fumigatus. This form of resistance has been linked to point alteration in 220, 138, and 54 codons from patient on azole treatment [34]. Plant pathogenic molds having tandem repeat which aid in resistance against sterol demethylation inhibitor fungicides have been reported [35]. Because fungi including A. fumigatus and other plant fungal pathogens share the same habitat, they are constantly exposed to fungicide pressure. Therefore, if Aspergillus species harboring TR/L98H resistance is present in the environment, the conidia can be widely dispersed by wind and may cause infection in the susceptible individual [9].

In Moshi, Tanzania, Azole-resistant Aspergillus fumigatus was isolated from soil known for extensive farming. It was reported that $20 \%$ of the environmental samples harbor azole-resistant Aspergillus fumigatus, of which 5.5\% was associated with TR46/Y122FT289A mutation and 20\% TR34/L98H mutation was isolated from woody debris and soil samples [20]. The isolation of Aspergillus fumigatus with
G54E mutation in Tanzania, Romania, and India from environmental samples is considered to occur in patients with prolonged exposure to azole [36]. The G54E mechanisms are responsible for $20.0 \%$ from India, 30.4\% from Romania, and $46.4 \%$ of resistant isolates from Tanzania [36].

\section{Conclusion}

There is significant triazole resistance among environmental isolates of Aspergillus probably ascribed to irrational use of fungicide in agriculture and calls for legislative mechanism for control of fungicide use. This is a grave public health concern given the limited resources and the limited antifungal options available for the susceptible patients.

\section{Ethical Approval}

The study was approved by the Kenya Medical Research Institute and Scientific and Ethics Review Unit (KEMRI/SERU/P000602/3031). There was no human participation or direct human contact. However, approved permission to access the farms was obtained from relevant institution or flower farms owner or individual farm owner.

\section{Conflicts of Interest}

The authors declare that they have no conflicts of interest.

\section{Acknowledgments}

This study was supported by the Kenya Medical Research Institute (KEMRI IRG Grant no. INNOV/IGR/019/2).

\section{References}

[1] G. D. Brown, D. W. Denning, N. A. R. Gow, S. Levitz, M. Netea, and T. White, "Human fungal infections: the hidden killers," Science Translational Medicine, vol. 4, pp. 165-167, 2012.

[2] E. Vermeulen, J. Maertens, and H. Schoemans, "Azoleresistant Aspergillus fumigatus due to TR46/Y121F/T289A mutation emerging in Belgium," Euro Surveillance, vol. 17, pp. 203-226, 2012.

[3] D. W. Denning, A. Pleuvry, and D. C. Cole, "Global burden of chronic pulmonary aspergillosis as a sequel to pulmonary 
tuberculosis," Bulletin of the World Health Organization, vol. 89, no. 12, pp. 864-872, 2011.

[4] A. Chowdhary, S. Kathuria, H. S. Randhawa, S. N. Gaur, C. H. Klaassen, and J. F. Meis, "Isolation of multiple triazoleresistant Aspergillus fumigatus strains carrying the TR/L98H mutations in the cyp51A gene in India," Journal of Antimicrobial Chemotherapy, vol. 67, no. 2, pp. 362-366, 2012.

[5] A. Bueid, "Azole antifungal resistance in Aspergillus fumigatus 2008 and 2009," Journal of Antimicrobial Chemotherapy, vol. 65, no. 10, pp. 2116-2118, 2010.

[6] P. R. Burgel, M. T. Baixench, M. Amsellem et al., "High prevalence of azole-resistant Aspergillus fumigatus in adults with cystic fibrosis exposed to itraconazole," Antimicrobial Agents and Chemotherapy, vol. 56, no. 2, pp. 869-874, 2012.

[7] S. R. Lockhart, J. P. Frade, K. A. Etienne, M. A. Pfaller, D. J. Diekema, and S. A. Balajee, "Azole resistance in Aspergillus fumigatus isolates from the ARTEMIS global surveillance study is primarily due to the TR/L98H mutation in the cyp51A gene," Antimicrobial Agents and Chemotherapy, vol. 55, no. 9, pp. 4465-4468, 2011.

[8] K. L. Mortensen, E. Mellado, C. Lass-Florl, J. L. RodriguezTudela, H. K. Johansen, and M. C. Arendrup, "Environmental study of azole-resistant Aspergillus fumigates and other aspergilli in Austria, Denmark, and Spain," Antimicrobial Agents and Chemotherapy, vol. 54, no. 11, pp. 4545-4549, 2010.

[9] K. L. Mortensen, R. H. Jensen, H. K. Johansen et al., “Aspergillus species and other molds in respiratory samples from patients with cystic fibrosis: a laboratory-based study with focus on Aspergillus fumigatus azole resistance," Journal of Clinical Microbiology, vol. 49, no. 6, pp. 2243-2251, 2011.

[10] E. Snelders, L. H. Van der, J. Kuijers et al., "Emergence of azole resistance in Aspergillus fumigatus and spread of a single resistance mechanism," PLoS Medicine, vol. 5, no. 11, article e219, 2008.

[11] E. Snelders, H. Venselaar, G. Schattenaar, A. Karawajczyk, and R. J. A. Verhoum, "The structure-function relationship of the Aspergillus fumigatus Cry51A L98H conversion by sitedirected mutagenesis: the mechanism of $\mathrm{L} 98 \mathrm{H}$ azole resistance," Fungal Genetics and Biology, vol. 48, no. 11, pp. 1062-1070, 2011.

[12] E. Snelders, S. M. Camps, A. Karawajczyk et al., "Triazole fungicides can induce cross-resistance to medical triazoles in Aspergillus fumigatus," PLoS One, vol. 7, no. 3, Article ID e31801, 2012.

[13] S. Ahmad, Z. Khan, F. Hagen, and F. M. Jacques, "Simple, low-cost molecular assays for TR34/L98H mutations in the cyp51A gene for rapid detection of triazole resistant Aspergillus fumigatus isolates," Journal of Clinical Microbiology, vol. 52, no. 6, pp. 2223-2227, 2014.

[14] S. Ahmad, L. Joseph, F. Hagen, J. F. Meis, and Z. Khan, "Concomitant occurrence of itraconazole resistant and susceptible stains of Aspergillus fumigatus in routine cultures," Journal of Antimicrobial Chemotherapy, vol. 70, no. 2, pp. 412-415, 2015.

[15] S. Ahmad, Z. Khan, F. Hagen, and J. F. Meis, "Occurrence of triazole resistant Aspergillus fumigatus with TR34/L98H mutations in outdoor and hospital environment in Kuwait," Environmental Research, vol. 133, pp. 20-26, 2014.

[16] N. P. Wiederhold, V. G. Gil, F. Gutierrez et al., "First detection of TR34/L98H and TR46/Y121F/T289A cyp51 mutations in Aspergillus fumigatus isolates in the United States," Journal of Clinical Microbiology, vol. 54, no. 1, pp. 168-171, 2016.
[17] M. Liu, R. Zeng, L. Zhang et al., "Multiple cyp51A based mechanism identified in azole resistant isolates of Aspergillus fumigatus from China," Antimicrobial Agents and Chemotherapy, vol. 59, no. 7, pp. 4321-4325, 2015.

[18] M. Nabili, P. Badiee, M. Moazeni et al., "High prevalence of clinical and environmental triazole resistant Aspergillus fumigatus in Iran: is it a challenging issue?," Journal of Medical Microbiology, vol. 65, no. 6, pp. 468-475, 2016.

[19] H. Badali, A. Vaezi, I. Haghani et al., "Environmental study of azole-resistant Aspergillus fumigatus with TR34/L98H mutations in the cyp51A gene in Iran," Mycoses, vol. 56, no. 6, pp. 659-663, 2013.

[20] A. Chowdhary, C. Sharma, M. van den Boom et al., "Multi azole resistant Aspergillus fumigatus in the environment in Tanzania," Journal of Antimicrobial Chemotherapy, vol. 69, no. 11, pp. 2979-2983, 2014.

[21] E. K. Kemoi, A. Nyerere, U. Gross, O. Bader, T. Gonoi, and C. C. Bii, "Diversity of azole resistant Aspergillus species Isolated from experience and naïve soils in Nairobi County and Naivasha Sub-County, Kenya," European Scientific Journal, vol. 13, no. 36, 2017.

[22] E. Vermeulen, J. Maertens, A. D. Bel et al., "Nationwide surveillance of azole resistance in Aspergillus diseases," Antimicrobial Agents and Chemotherapy, vol. 59, no. 8, pp. 4569-4576, 2015.

[23] O. Bader, M. Weig, U. Reichard et al., "Cyp51A based mechanism of Aspergillus fumigatus azole drug resistance present in clinical samples from Germany," Antimicrobial Agents and Chemotherapy, vol. 57, no. 8, pp. 3513-3517, 2013.

[24] O. Bader, J. Tunnermann, A. Dudakova, M. Tangwattanachuleeporn, M. Weig, and U. Gross, "Environmental isolates of azole resistant Aspergillus fumigatus in Germany," Antimicrobial Agents and Chemotherapy, vol. 59, no. 7, pp. 4356-4359, 2015.

[25] E. Snelders, R. A. G. Huis in't Veld, J. M. M. A. Rijis, G. H. J. Kema, W. J. G. Melchers, and P. E. Verweiji, "Possible environmental origin of resistance of Aspergillus fumigatus to medical triazoles," Applied and Environmental Microbiology, vol. 75, no. 12, pp. 4053-4057, 2009.

[26] Clinical and Laboratory Standards Institute, Reference Method for Broth Dilution Antimicrobial Susceptibility Testing of Filamentous Fungi-Second Edition: Standard M38-A2, CLSI, Wayne, PA, USA, 2008.

[27] M. C. Arendrup, M. Cuenca-Estrella, C. Lass-Flord, and W. W. Hope, "European committee on antimicrobial susceptibility testing subcommittee on antifungal testing. EUCAST technical note on Aspergillus and Amphotericin B, itraconazole and posaconazole," Clinical Microbiology and Infection, vol. 18, no. 7, pp. E248-E250, 2012

[28] A. Chowdhary, S. Kathuria, and J. Xu, "Clonal expansion and emergence of environmental multiple triazole resistant Aspergillus fumigatus strains carrying the TR34/L98H mutations in the cyp51A gene in India," PLoS One, vol. 7, no. 12, Article ID e52871, 2012.

[29] E. P. Verweji, H. G. Kema, and J. W. Melchers, "Triazole fungicides and the selection of resistance to medical triazoles in the opportunistic mould Aspergillus fumigatus," Pest Management Science, vol. 69, no. 2, pp. 165-170, 2013.

[30] A. Abdolrasouli, J. Rhodes, M. A. Beale et al., "Genomic context of azole resistance mutations in Aspergillus fumigatus determined using whole-genome sequencing," MBio, vol. 6, no. 4, article e00536, 2015.

[31] E. Mellado, G. Garcia-Effron, L. Alcazar-Fuoli et al., "A new Aspergillus fumigatus resistance mechanism conferring in 
vitro cross-resistance to azole antifungals involves a combination of CYP51A alterations," Antimicrobial Agents and Chemotherapy, vol. 51, no. 6, pp. 1897-1904, 2007.

[32] J. W. Van der Linden, E. Snelders, G. A. Kampinga et al., "Clinical implication of azole resistance in Aspergillus fumigatus, the Netherlands, 2007-2009," Emerging Infectious Diseases, vol. 17, no. 10, pp. 1846-1854, 2011.

[33] R. S. Shapiro, N. Robbins, and L. E. Cowen, "Regulatory circuitry governing fungal development, drug resistance and disease," Microbiology and Molecular Biology Reviews, vol. 75, no. 2, pp. 213-267, 2011.

[34] M. C. Arendrup, E. Mavridou, K. L. Mortensen et al., "Development of azole resistance in Aspergillus fumigatus during azole therapy associated with change in virulence," PLoS One, vol. 5, no. 4, Article ID e10080, 2010.

[35] E. Snelders, W. J. Melchers, and P. E. Verweij, "Azole resistance in Aspergillus fumigatus: a new challenge in the management of invasive aspergillosis?," Future Microbiology, vol. 6, no. 3, pp. 335-347, 2011.

[36] C. Sharma, F. Hagen, R. Moroti, J. F. Meis, and A. Chowdhary, "Triazole-resistant Aspergillus fumigatus harbouring G54 mutation: is it de novo or environmentally acquired?," Journal of Global Antimicrobial Resistance, vol. 3, no. 2, pp. 69-74, 2015. 


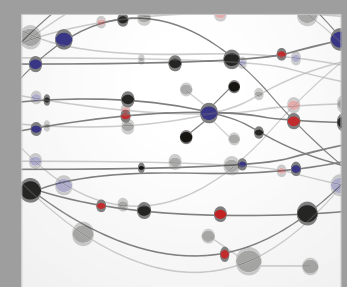

The Scientific World Journal
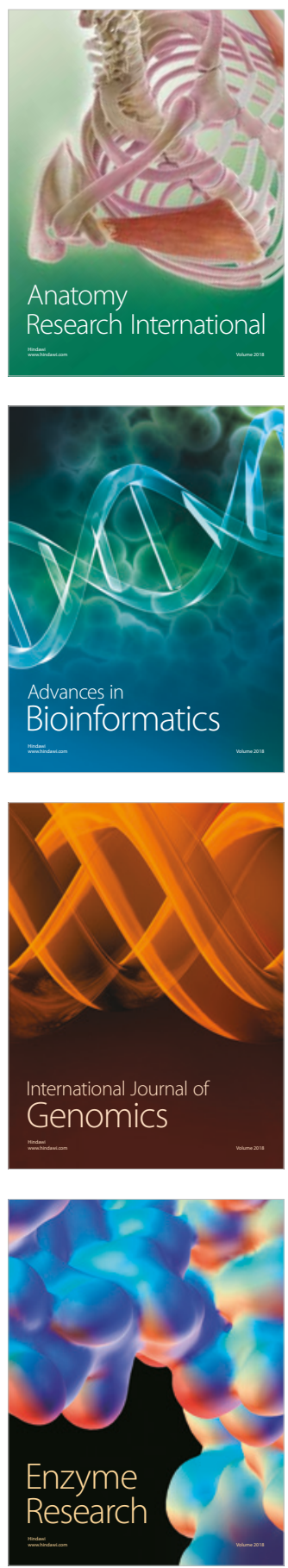
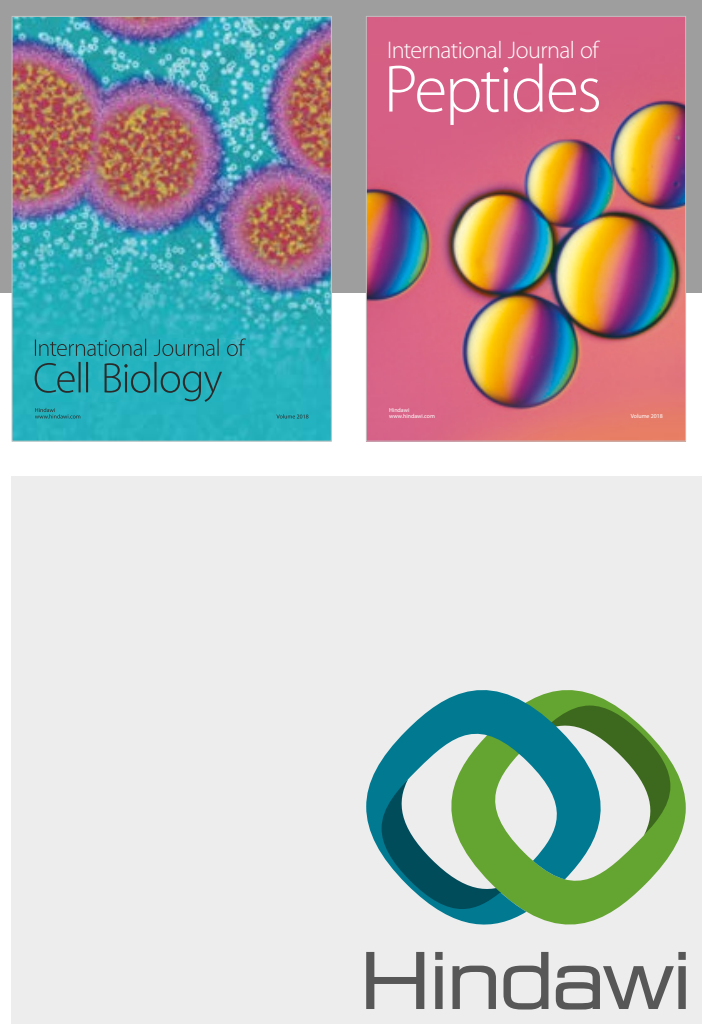

Submit your manuscripts at

www.hindawi.com
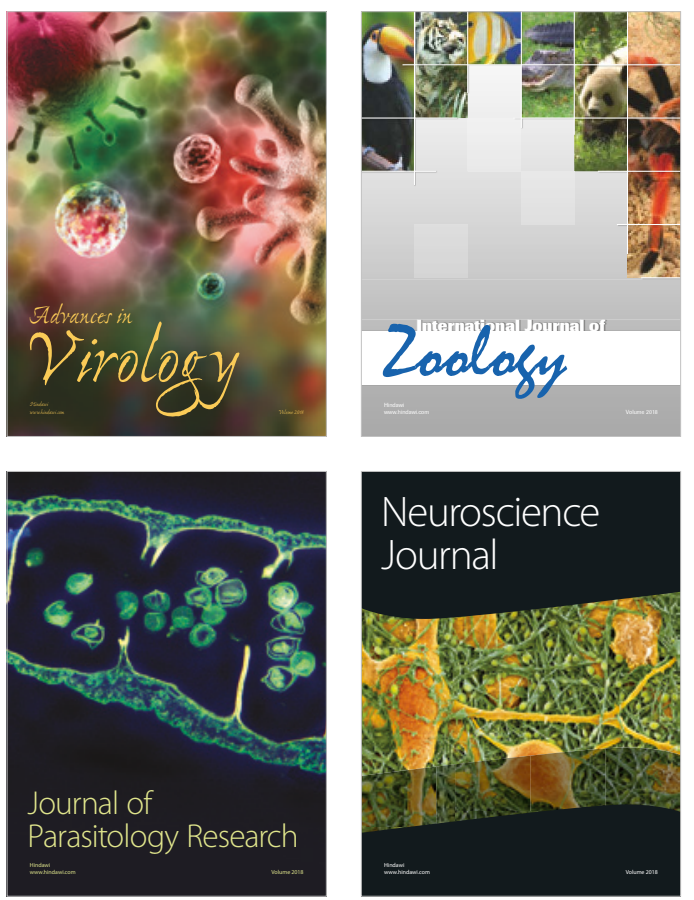
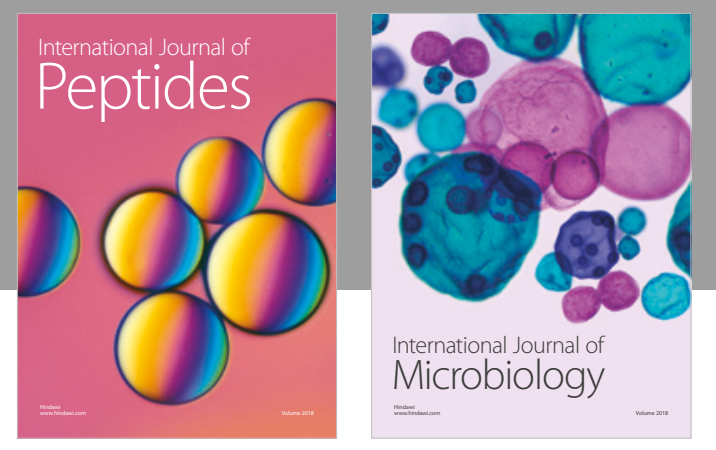

nternational Journal of Microbiology
Journal of
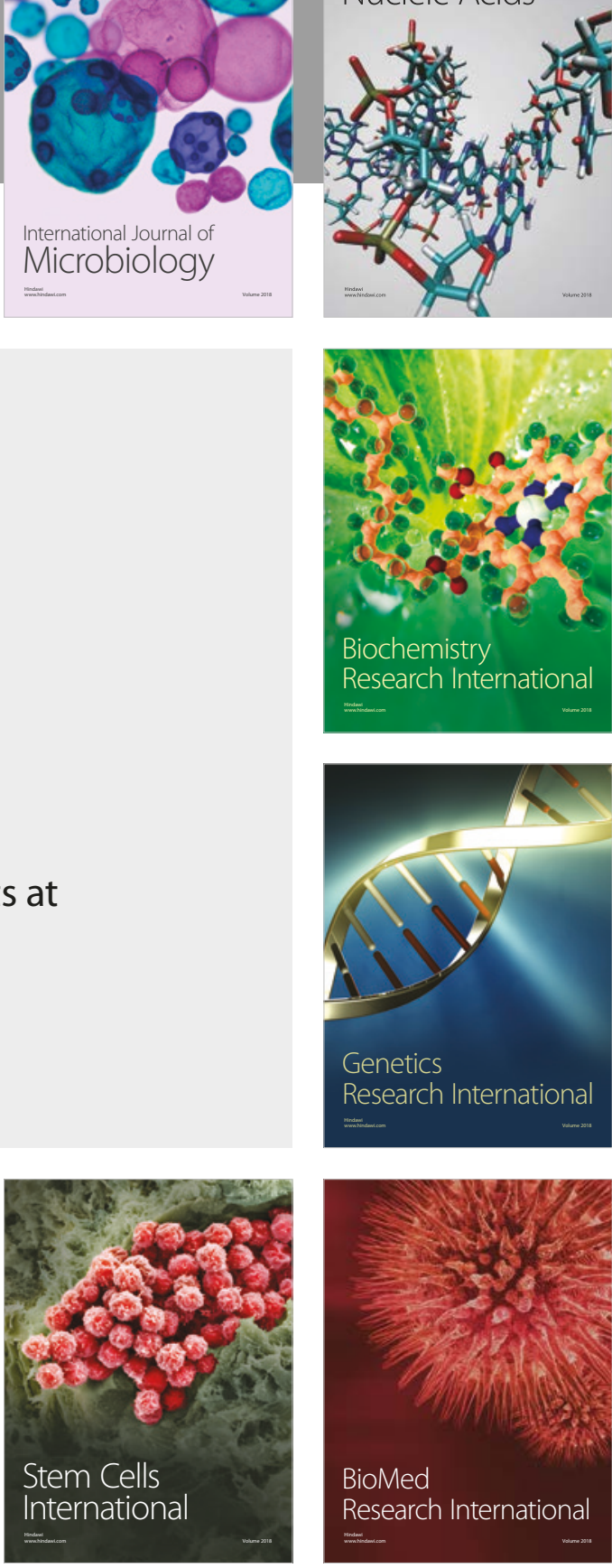
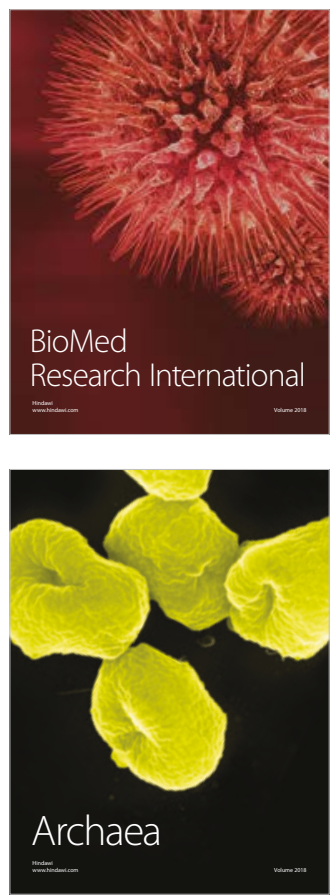